\title{
Association between prognostic survival of human colorectal carcinoma and ZNRF3 expression
}

This article was published in the following Dove Press journal:

OncoTargets and Therapy

28 October 2016

Number of times this article has been viewed

\author{
Nanhui Yu ${ }^{1,2}$ \\ Hong Zhu' \\ Yiming Tao' \\ Yongpan Huang ${ }^{3}$ \\ Xiangping Song' \\ Yuan Zhou' \\ Yuqiang $\mathrm{Li}^{\prime}$ \\ Qian Pei' \\ Qiurong Tan ${ }^{2}$ \\ Haiping Pei' \\ 'Department of Gastrointestinal \\ Surgery, Xiangya Hospital, Central \\ South University, ${ }^{2}$ Department of \\ Pharmacy, Changsha Hospital for \\ Maternal \& Child Health Care, \\ ${ }^{3}$ Department of Pharmacology, \\ College of Pharmacy, Central South \\ University, Changsha, People's \\ Republic of China
}

Purpose: E3 ubiquitin ligase ZNRF3 is linked to the pathogenesis of diseases and tumorigenesis. The present study aims to explore the expression of ZNRF3 and its association with prognostic survival of human colorectal carcinoma.

Methods: A follow-up survey of 168 patients with colorectal carcinoma was performed, and specimens of colorectal tissues were collected for immunohistochemistry and Western blotting analyses. Furthermore, overexpression of ZNRF3 using transient transfection with the recombinant pEGFP-ZNRF3 plasmid and detection of apoptosis and proliferation were performed in HCT-116 cells.

Results: The results showed a diverse feature of ZNRF3 staining, such as strong, moderate, weak, or negative, in colorectal carcinoma tissues. Interestingly, univariate Kaplan-Meier analysis showed that cases with strong or moderate expression of ZNRF3 showed an optimistic disease-free survival and overall survival compared with negative expression of ZNRF3, and multivariate Cox model demonstrated ZNRF3 as an independent prediction index for overall survival and disease-free survival. In vitro, the overexpression of ZNRF3 was related to the negative regulation of $\mathrm{Wnt} / \beta$-catenin pathway and referred to an induction of apoptosis and suppression of proliferation in ZNRF3-transfected HCT-116 cells.

Conclusion: Our results suggest that the higher expression of ZNRF3 acts as a novel marker of indicating the optimistic prognosis of colorectal carcinoma by suppressing cancer cell growth and facilitating apoptosis.

Keywords: colorectal cancer, prognostic survival, E3 ubiquitin ligase ZNRF3, relationship

\section{Introduction}

Colorectal carcinoma is the third most common type of fatal malignancy in the People's Republic of China and is the second highest cause of cancer-related death worldwide. ${ }^{1}$ It is a multifactorial disease that can be affected by lifestyle, environment, and germinal mutations. ${ }^{2,3}$ With the development of chemotherapy and radiation therapy, the incidence and mortality of colorectal carcinoma showed decreasing levels. However, the 5 -year survival rate of patients with colorectal carcinoma remains unsatisfactory due to metastasis leading to poor outcomes. ${ }^{4,5}$ Recently, attention has been paid on identifying accurately the biological characteristics of tumors to predict the prognosis in patients with colorectal carcinoma. It is well appreciated that $\mathrm{Wnt} / \beta$-catenin signaling is a critical pathway in the regulation of cell growth and development. ${ }^{6,7}$ In animals, the Wnt signal transduction cascade controls a wide variety of biological phenomena and is involved in tissue homeostasis throughout development and into adulthood. At the same time, aberrant Wnt signaling underlies most of the pathological pathways and can significantly affect proliferation and apoptosis in human cancer. ${ }^{8}$ However, effective Wnt inhibitors have not been developed, and even if they did exist, they would not
Correspondence: Haiping Pei Department of Gastrointestinal Surgery, Xiangya Hospital, Central South University, Changsha 410008, People's Republic of China Email haiping1977pei@I63.com 
inhibit Wnt signaling in tumors with certain pathway mutations. ZNRF3, a unique transmembrane E3 ubiquitin ligase, suppresses $\beta$-catenin signaling initiated by endogenous Wnt proteins, which distinguishes ZNRF3 from other negative regulators of Wnt signaling, such as APC, AXIN, and GSK3 $\mathrm{a} / \mathrm{b} .{ }^{9}$ The expression and function of ZNRF3 have been examined in gastric adenocarcinoma, and the mechanisms through which it suppresses proliferation and induces apoptosis are well understood. ${ }^{8}$ However, the characteristics of ZNRF3 expression and their association with colorectal carcinoma remain unclear. Here, we aimed to investigate the profile of prognostic survival in patients with colorectal carcinoma. In addition, ZNRF3 expression in colorectal cancer tissues was analyzed by the method of immunoblotting. Furthermore, the effects of ZNRF3 overexpression on proliferation and apoptosis were determined using HCT-116 cell line.

\section{Materials and methods}

\section{Follow-up study}

After obtaining approval from the Ethics Committee of Central South University and written informed consent from the patients, a follow-up study of 168 patients with colorectal carcinoma (males: 100; females: 68, average age: 55.75 years; range: $23-82$ years) was performed. The follow-up patients who had undergone curative operations based on the National Comprehensive Cancer Network Practice Guidelines for colon cancer were compared with respect to their disease-free survival (DFS) and overall survival (OS), which were defined as the interval between the initial surgery and clinically or radiologically proven recurrence/metastasis or death, respectively. The follow-up was completed on March 29, 2015, with a median patient follow-up time of 62.5 months (range, 8-77 months). At the last follow-up, 76 patients were still alive, 80 patients died of colorectal carcinoma metastasis, and eight patients died of other diseases. In addition, four patients were lost to follow-up.

\section{Colorectal carcinoma tissue and immunohistochemistry analysis}

The colorectal tissue samples were collected from 168 patients who had undergone surgery at the Xiangya Hospital, Central South University, between October 2008 and October 2009, and 168 samples of adjacent normal colorectal tissue were also obtained as controls. All the tissue specimens were divided into two parts; one part was frozen promptly by liquid nitrogen and the other was fixed in $10 \%(\mathrm{v} / \mathrm{v})$ formalin and embedded in paraffin for immunohistochemistry (IHC) analysis. Paraffin wax-embedded biopsy samples were cut into sections and mounted on 3-aminopropyltriethoxysilane-coated glass slides. For IHC experiments, tissue sections were incubated with primary rabbit antihuman polyclonal antibody ZNRF3 (1:150 dilution, PAB23049; Abnova Corporation, Walnut, CA, USA) overnight at $4^{\circ} \mathrm{C}$. Then, sections were washed three times for 5 minutes and incubated with polymer enhancer for 20 minutes. After washing thoroughly with PBS, the sections were incubated with secondary antibody (polymeric HRP-labeled antirabbit immunoglobulin G) for 30 minutes at room temperature and washed three times. Tissue staining was performed with diaminobenzidine. The sections were counterstained with hematoxylin, dehydrated, and mounted in resin.

\section{Plasmids, cell culture, and transfection}

A plasmid encoding pEGFP-ZNRF3 was purchased from Sigma-Aldrich Co. (St Louis, MO, USA). HCT-116 cells were maintained in Dulbecco's Modified Eagle's Medium (DMEM) supplemented with 10\% (v/v) fetal bovine serum in an incubator (Thermo Fisher Scientific, Waltham, MA, USA) with $5 \%(\mathrm{v} / \mathrm{v})$ humidity under a $\mathrm{CO}_{2}$ atmosphere at $37^{\circ} \mathrm{C}$. The cells were passaged every $2-3$ days. Cells were transfected with $100 \mathrm{nM}$ pEGFP-ZNRF3 or pEGFP-con238 (negative control) using Lipofectamine 2000 (Thermo Fisher Scientific), according to the manufacturer's instructions.

\section{Cell migration and apoptosis assay}

The assay of cell migration and invasion was performed in a 24-well plate with $8 \mathrm{~mm}$ pore size chamber inserts. For migration assays, $5 \times 10^{4}$ cells/well were placed into the upper chamber with the noncoated membrane. For invasion assays, $2 \times 10^{5}$ cells/well were placed into the upper chamber with the matrigel-coated membrane, which was diluted with serum-free culture medium. Then, the cells were suspended in $250 \mu \mathrm{L}$ of serum-free DMEM and seeded into the upper chamber, and $750 \mu \mathrm{L}$ of DMEM supplemented with $10 \%$ fetal bovine serum was added. After incubation for 24 hours, the chambers were fixed with methanol and stained with $0.1 \%$ crystal violet for 15 minutes. Images were captured with an Olympus BX83 fluorescence microscope.

Cell apoptosis was measured at 72 hours posttransfection by flow cytometry using the Annexin V-FITC Apoptosis Detection kit (88-8007; eBioscience, San Diego, CA, USA), according the manufacturer's instructions. Briefly, HCT -116 cells were digested with $0.25 \%(w / v)$ trypsin and resuspended in $195 \mu \mathrm{L}$ Annexin V-FITC binding buffer at a final concentration of $5 \times 10^{4}-1 \times 10^{5}$ cells. Next, $5 \mu \mathrm{L}$ Annexin V-FITC was added to $195 \mu \mathrm{L}$ cell suspension. After a 10-minute incubation at room temperature in the dark, the cell suspension was centrifuged at $1,000 \times g$ for 5 minutes 
and then resuspended in $190 \mu \mathrm{L}$ Annexin V-FITC-binding buffer and $10 \mu \mathrm{L}$ propidium iodide on ice in the dark. The number of stained cells was assessed using a flow cytometer (FACSCalibur; BD, Franklin Lakes, NJ, USA).

\section{Cell proliferation assay}

The effect of ZNRF3 on HCT-116 cell proliferation was determined using a cell proliferation assay. Cells were plated at a density of 5,000 cells/well in 96-well plates in the presence of DMEM. CCK-8 assays were performed at 24 hours, 48 hours, 72 hours, and 96 hours posttransfection. Next, $10 \mu \mathrm{L}$ of the cell proliferation reagent WST-8 was added to each well, and the cells were incubated for 2 hours at $37^{\circ} \mathrm{C}$. Viable cell counts were estimated by measuring the optical density at $450 \mathrm{~nm}$, as the amount of dye generated by the dehydrogenase reaction in cells is directly proportional to the number of living cells.

\section{Western blotting analyses of ZNRF3, $\beta$-catenin, and TCF-4}

Total protein was extracted from tissue samples or cultured cells using RIPA lysis buffer supplemented with protease and phosphatase inhibitors. Protein concentration was determined using a Bradford Protein Assay kit (Bio-Rad Laboratories Inc., Hercules, CA, USA). Equal amounts of total protein $(30 \mu \mathrm{g})$ were separated by sodium dodecyl sulfate polyacrylamide gel electrophoresis $(10 \%)$, followed by electrophoretic transfer onto nitrocellulose membranes (GE Healthcare UK Ltd, Little Chalfont, UK). The blots were incubated overnight at $4^{\circ} \mathrm{C}$ with primary antibody, rabbit antihuman polyclonal to ZNRF3-C-terminal, anti- $\beta$-catenin rabbit polyclonal antibody (ab6302), and rabbit polyclonal TCF-4 antibody (ab185736) (the proportion of dilution was 1:800, 1:600, and 1:800, respectively; Abcam, Cambridge, UK), followed by polymeric HRPlabeled antirabbit immunoglobulin G (the secondary antibody; Promega Corporation, Fitchburg, WI, USA) for 2 hours at room temperature. The bound antibodies were detected using the SuperSignal Western Blotting Kit (Thermo Fisher Scientific). To provide a quality control, GAPDH antibody (Beyotime Institute of Biotechnology, Haimen, Jiangsu, People's Republic of China) was used as the internal control in each group.

\section{Statistical analysis}

All statistical analyses were performed using the SPSS 19.0 software program (IBM Corporation, Armonk, NY, USA). The results are presented as the mean \pm standard error of the mean. Differences between the two groups were compared using the independent-samples $t$-test, $\chi^{2}$ test, or Fisher's exact test, as appropriate. The patient survival curve was analyzed using the Kaplan-Meier method with the logrank test. A Cox proportional hazards model was used to calculate univariate and multivariate hazard ratios for the variables. A $P$-value of $<0.05$ was considered statistically significant.

\section{Results}

\section{Analysis of ZNRF3 expression}

Evaluation of ZNRF3 expression applied a method of stereological cell counts, and the positive result of staining was yellow or brown yellow. The absence of positive cells was indicative of a negative result. Positive cells $<25 \%$ indicated a result of weakly positive. Positive cells ranging from $25 \%$ to $50 \%$ indicated a result of moderately positive. More than $50 \%$ of positive cells indicated strong positive expression. ${ }^{10-12}$ As shown in Figure 1A-D, the IHC results of colorectal carcinoma tissue showed 134 positive and 34 negative for ZNRF3 expression. Furthermore, ZNRF3-positive tissues were classified as follows: 42 weak positive, 62 moderate positive, and 30 strong positive.

The correlation analysis showed that $\mathrm{T}$ stage, $\mathrm{N}$ stage, American Joint Committee on Cancer stage, and differentiation were significantly associated with ZNRF3 expression $(P<0.05)$, while age, sex, and tumor location were not significantly associated with ZNRF3 expression $(P>0.05$; Table 1). Interestingly, the proportion of ZNRF3 "strong positive" in adjacent normal colorectal tissue was significantly higher compared with colorectal carcinoma tissue $(P<0.05$; Table 2). The results of Western blotting analysis further demonstrated the consistence with results of ZNRF3 IHC in adjacent normal colorectal tissues and in colorectal carcinoma tissue that were consistent with that of IHC analysis, as shown in Figure $2 \mathrm{~A}$ and $\mathrm{B}$.

\section{ZNRF3 expression is associated with optimistic prognosis in colorectal carcinoma}

To evaluate the prognosis significance of ZNRF3 for distant metastasis, Kaplan-Meier curves with a log-rank test for OS and DFS were generated in the 168 patients who accepted radical colectomy. The results showed that patients with ZNRF3 strong positive or moderate positive tumors showed a higher DFS or OS rate compared with patients with ZNRF3-negative tumors (Figure 3; log-rank test, $P<0.05$ ). Furthermore, the univariate Cox proportional hazards model showed a significant hazard ratio (HR) of DFS or OS between the ZNRF3 strong positive or moderate positive and ZNRF3negative groups after surgery (DFS-HR $=0.246$ or 0.364 ; OS-HR $=0.286$ or $0.452, P<0.05$; Table 3 ). In addition, 

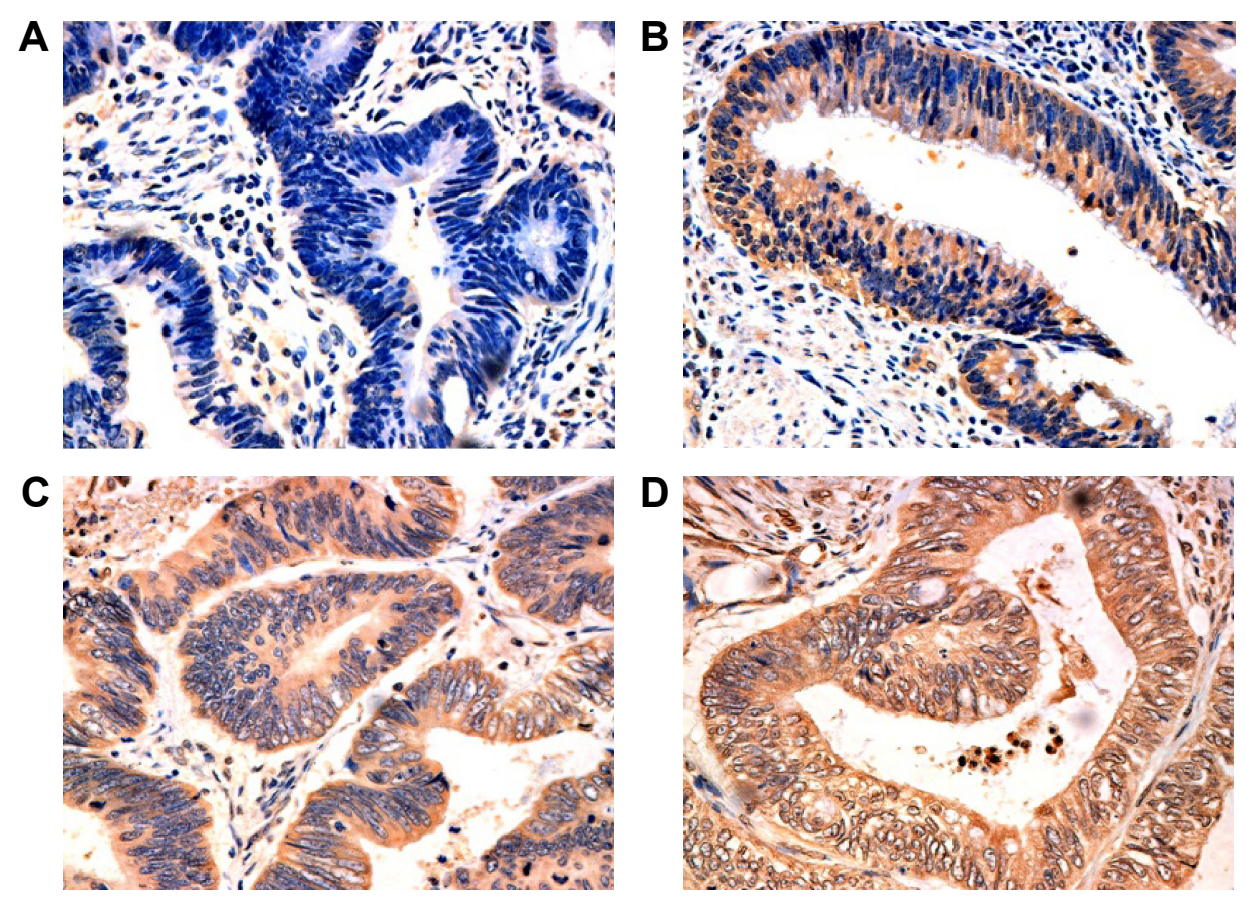

Figure I Immunohistochemical analysis of ZNRF3 in colorectal cancer tissue.

Notes: (A) The negative expression of ZNRF3 in colorectal cancer tissue $(\times 200)$. (B) The weakly positive expression of ZNRF3 in colorectal cancer tissue $(\times 200)$. (C) The moderately positive expression of ZNRF3 in colorectal cancer tissue $(\times 200)$. (D) The strong positive expression of ZNRF3 in colorectal cancer tissue $(\times 200)$.

Table I Clinicopathological features and ZNRF3 protein expression in colorectal carcinoma tissues

\begin{tabular}{|c|c|c|c|c|c|c|}
\hline \multirow{2}{*}{$\begin{array}{l}\text { Clinicopathological } \\
\text { parameters }\end{array}$} & \multirow{2}{*}{$\begin{array}{l}\text { Case } \\
\text { number }\end{array}$} & \multicolumn{4}{|c|}{ Expression of ZNRF3, n (\%) } & \multirow{2}{*}{$\begin{array}{l}\chi^{2} \text { test, } \\
P \text {-value }\end{array}$} \\
\hline & & Negative & Weak & Moderate & Strong & \\
\hline \multicolumn{7}{|l|}{ Age (years) } \\
\hline$<65$ & 136 & $28(20.6)$ & $34(25.0)$ & $48(35.3)$ & $26(19.1)$ & \multirow[t]{2}{*}{0.899} \\
\hline$\geq 65$ & 32 & $6(18.8)$ & $8(25.0)$ & $14(43.8)$ & $4(12.5)$ & \\
\hline \multicolumn{7}{|l|}{ Sex } \\
\hline Male & 100 & $18(18.0)$ & $22(22.0)$ & $40(40.0)$ & $20(20.0)$ & \multirow[t]{2}{*}{0.708} \\
\hline Female & 68 & $16(23.50)$ & $20(29.4)$ & $22(32.4)$ & $10(14.70)$ & \\
\hline \multicolumn{7}{|l|}{ Tumor location } \\
\hline Right & 66 & $10(15.2)$ & $22(33.3)$ & $26(39.4)$ & $8(12.1)$ & \multirow[t]{4}{*}{0.328} \\
\hline Transverse & 62 & $14(22.6)$ & $14(22.6)$ & $16(25.8)$ & $18(29.0)$ & \\
\hline Left & 24 & $4(16.7)$ & $6(25.0)$ & $12(50.0)$ & $2(8.3)$ & \\
\hline Sigmoid colon & 16 & $6(37.5)$ & $0(0.0)$ & $8(50.0)$ & $2(12.5)$ & \\
\hline \multicolumn{7}{|l|}{ T stage } \\
\hline TI & 50 & $4(8.0)$ & $6(12.0)$ & $28(56.0)$ & $12(24.0)$ & \multirow[t]{4}{*}{0.034} \\
\hline $\mathrm{T} 2$ & 58 & $14(24.1)$ & $10(17.2)$ & $26(44.8)$ & $8(13.8)$ & \\
\hline T3 & 44 & $12(27.3)$ & $20(45.5)$ & $4(9.1)$ & $8(18.2)$ & \\
\hline $\mathrm{T} 4$ & 16 & $4(25.0)$ & $6(37.5)$ & $4(25.0)$ & $2(12.5)$ & \\
\hline \multicolumn{7}{|l|}{$N$ stage } \\
\hline No & 50 & $2(4.0)$ & $6(12.0)$ & $30(60.0)$ & $12(24.0)$ & \multirow[t]{3}{*}{0.009} \\
\hline $\mathrm{NI}$ & 34 & $4(1 \mathrm{I} .80)$ & $10(29.4)$ & I4 (4I.2) & $6(17.6)$ & \\
\hline N2 & 84 & $28(33.3)$ & $26(31.0)$ & I8 (2 I.4) & $12(14.3)$ & \\
\hline \multicolumn{7}{|l|}{ AJCC stage } \\
\hline I & 44 & $0(0.0)$ & $6(13.6)$ & $28(63.6)$ & $10(22.7)$ & \multirow[t]{3}{*}{0.002} \\
\hline II & 82 & $16(19.5)$ & $22(26.8)$ & $26(31.7)$ & $18(22.0)$ & \\
\hline III & 42 & I 8 (42.9) & $14(33.3)$ & $8(19.0)$ & $2(4.8)$ & \\
\hline \multicolumn{7}{|l|}{ Differentiation } \\
\hline High & 48 & $2(4.2)$ & $6(12.5)$ & $25(52.1)$ & 15 (31.2) & \multirow[t]{3}{*}{0.003} \\
\hline Moderate & 80 & $14(17.5)$ & $22(27.5)$ & 31 (38.8) & $13(16.2)$ & \\
\hline Low & 40 & $18(45.0)$ & $14(35.0)$ & $6(15.0)$ & $2(5.0)$ & \\
\hline
\end{tabular}

Abbreviations: AJCC, American Joint Committee on Cancer; T, depth of invasion; N, lymph node metastasis. 
Table 2 Immunohistochemical analysis of ZNRF3 protein in colorectal cancer tissue and adjacent normal colorectal tissue

\begin{tabular}{llll}
\hline Samples & $\begin{array}{l}\text { Adjacent normal } \\
\text { colorectal tissue (n) }\end{array}$ & $\begin{array}{l}\text { Colorectal } \\
\text { cancer tissue (n) }\end{array}$ & $\begin{array}{l}\chi^{2} \text { test, } \\
\text { P-value }\end{array}$ \\
\hline Number of cases & 168 & 168 & $<0.05$ \\
Negative & 4 & 34 & \\
Weak & 7 & 42 & \\
Moderate & 15 & 62 & \\
Strong & 142 & 30 & \\
\hline
\end{tabular}

$\mathrm{T}$ staging and $\mathrm{N}$ staging were correlated with OS and DFS $(P<0.05)$. The further multivariate Cox proportional hazards model revealed that ZNRF3 expression was an independent prognostic marker for tumor recurrence and overall survival (DFS-HR $=0.574$; OS-HR $=0.581, P<0.05$; Table 4). Generally, patients with ZNRF3 strong positive or moderate positive tumors had an optimistic DFS and OS compared with patients with ZNRF3-negative tumors.

\section{Effects of ZNRF3 overexpression on apoptosis and proliferation in HCT-II 6 cells}

To examine the effect of ZNRF3 overexpression on apoptosis and proliferation in HCT-116 cells, these cells were transfected with pEGFP-ZNRF3 for 72 hours, and then cells' migration, proliferation, and apoptosis were determined using FACS and the ELx800 analysis (BioTek Instruments, Inc, Winooski, VT, USA). As shown in Figure 4A-D, compared with the negative control group, we observed a decrease in cell migration and a significant increase in

A
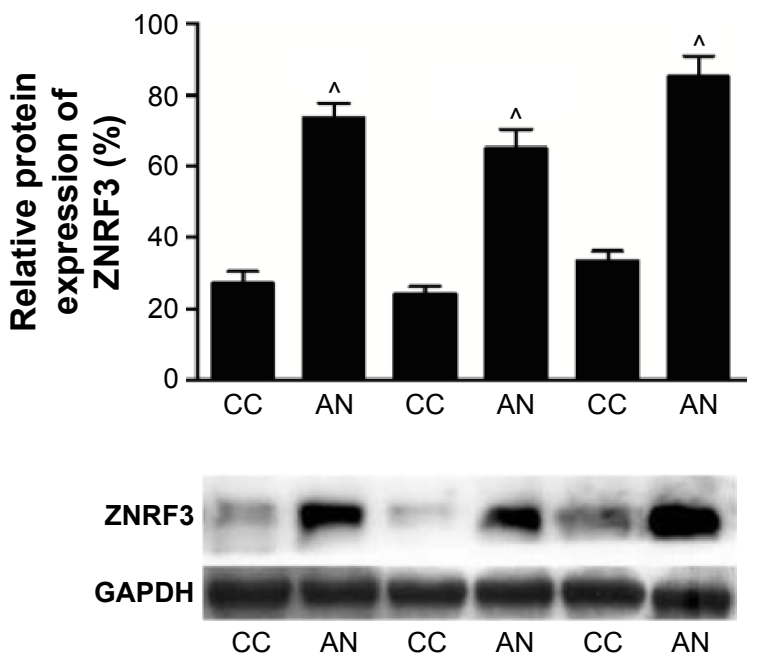

apoptosis in HCT-116 cells with ZNRF3 overexpression $(P<0.05)$, and we also found that overexpression of ZNRF3 significantly suppressed proliferation and survival of cells in a time-dependent manner (Figure 4E). These results indicated that overexpression of ZNRF3 could induce apoptosis and suppress proliferation in HCT-116 cells, further supporting a potential anticancer role for ZNRF3 in colorectal carcinoma (Table 5).

\section{The expression levels of $\beta$-catenin and TCF-4 protein in human colorectal carcinoma}

To investigate the effects of ZNRF3 on the Wnt/ $\beta$-catenin pathway, the expression of $\beta$-catenin and TCF- 4 proteins was detected in ZNRF3-overexpressed HCT-116 cells. As shown in Figure 5, following up transfection with either pEGFP-ZNRF3, an empty pEGFP vector (negative control) or no vector (blank control) in HCT-116 cells, the expression levels of both $\beta$-catenin and TCF-4 proteins showed a significant downregulation in ZNRF3-overexpressed HCT-116 cells compared with the negative and blank controls. These results demonstrated a negative regulation role of ZNRF3 protein in the Wnt signaling pathway.

\section{Discussion}

E3 ubiquitin ligase ring finger 43 (RNF43), the functional homolog of ZNRF3, is an important member of the E3 ubiquitin ligase family, and it regulates Wnt pathway turnover and activity of many functional proteins. ${ }^{13,14}$ Several previous

B
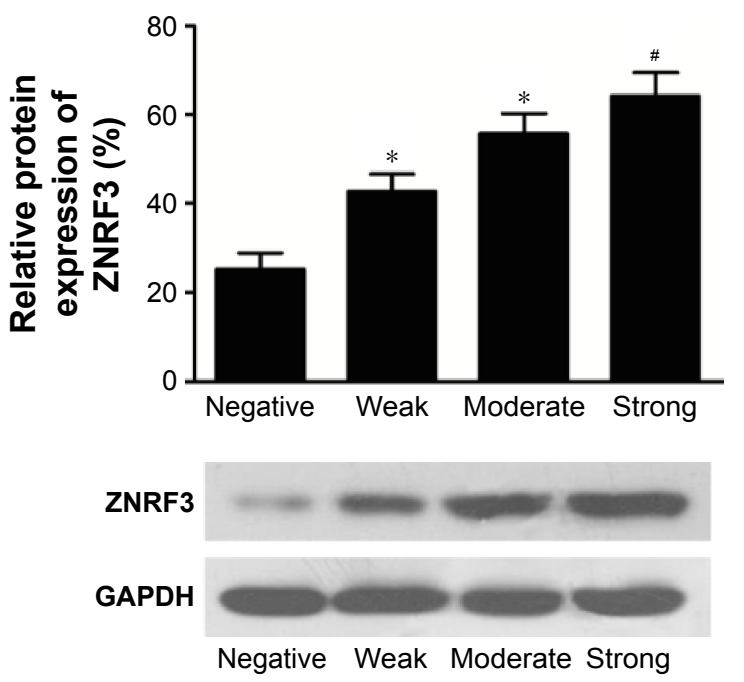

Figure 2 Expression of ZNRF3 protein in tissues.

Notes: (A) Expression of ZNRF3 protein in CC tissues and AN colorectal tissues. The levels of ZNRF3 protein were relatively lower in CC samples compared with AN colorectal tissues. $\wedge P<0.05$ compared with CC. (B) Expression of ZNRF3 protein in tissues; negative, weak positive, moderate positive, and strong positive. The results of ZNRF3 expression were consistent with that of immunohistochemical analysis. ${ }^{*} P<0.05$ compared with negative; ${ }^{\# P<0.0 I}$ compared with negative.

Abbreviations: AN, adjacent normal; CC, colorectal carcinoma. 

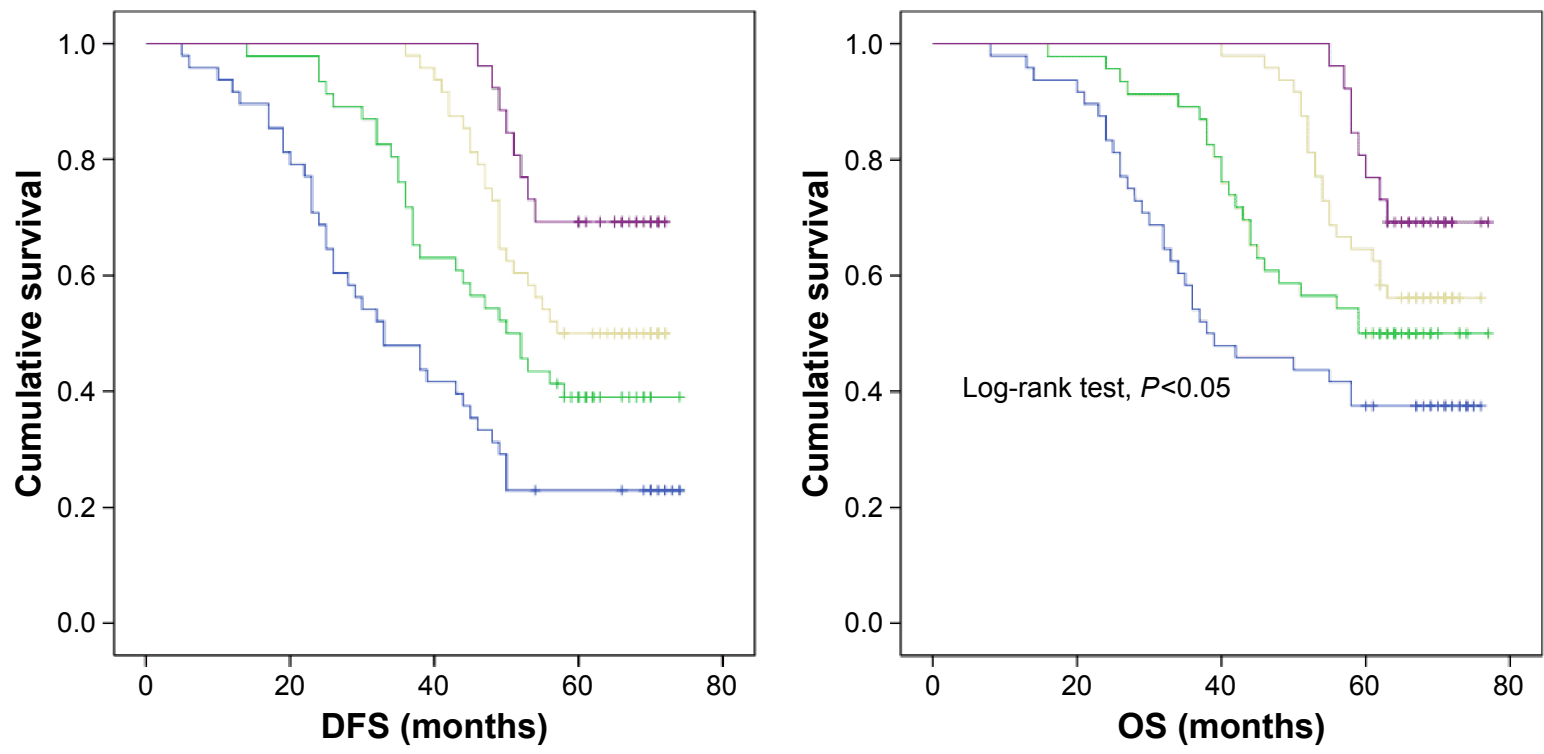

\begin{tabular}{|c|c|c|c|}
\hline \multicolumn{4}{|l|}{ ZNRF3 } \\
\hline$\neg$ Negative & + Negative censored & Moderate & Moderate censored \\
\hline$\neg$ Weak & + Weak censored & $\neg$ Strong & $\uparrow$ Strong censored \\
\hline
\end{tabular}

Figure 3 Distribution of Kaplan-Meier survival functions of OS and DFS in patients with different ZNRF3 expressions.

Abbreviations: DFS, disease-free survival; OS, overall survival.

Table 3 Univariate Cox proportional hazards model for DFS and OS

\begin{tabular}{|c|c|c|c|c|c|c|}
\hline \multirow[t]{2}{*}{ Variable } & \multicolumn{3}{|l|}{ DFS } & \multicolumn{3}{|l|}{ OS } \\
\hline & HR & $95 \% \mathrm{Cl}$ & $P$-value & HR & $95 \% \mathrm{Cl}$ & $P$-value \\
\hline \multicolumn{7}{|l|}{ Age (years) } \\
\hline$<65$ & - & & & - & & \\
\hline$\geq 65$ & 1.396 & $0.456-4.275$ & 0.559 & 1.875 & $0.613-5.738$ & 0.271 \\
\hline \multicolumn{7}{|l|}{ Sex } \\
\hline Male & - & & & - & & \\
\hline Female & 1.190 & $0.626-2.262$ & 0.595 & 0.970 & $0.508-|.85|$ & 0.925 \\
\hline \multicolumn{7}{|l|}{ Tumor location } \\
\hline Right & - & & & - & & \\
\hline Transverse & 1.012 & $0.378-2.709$ & $0.98 \mathrm{I}$ & 1.448 & $0.540-3.88 \mid$ & 0.462 \\
\hline Left & 1.167 & $0.307-4.44 \mid$ & 0.821 & 1.900 & $0.498-7.251$ & 0.348 \\
\hline Sigmoid colon & 1.389 & $0.284-6.790$ & 0.685 & 2.262 & $0.462-11.082$ & 0.314 \\
\hline \multicolumn{7}{|l|}{ T staging } \\
\hline $\mathrm{TI}$ & - & & & - & & \\
\hline $\mathrm{T} 2$ & 1.011 & $0.347-2.949$ & 0.984 & 1.188 & $0.406-3.478$ & 0.753 \\
\hline T3 & 1.896 & $0.588-6.112$ & 0.284 & 1.061 & $0.335-3.357$ & 0.920 \\
\hline $\mathrm{T} 4$ & 7.583 & $0.809-71.046$ & 0.076 & 8.909 & $0.949-83.616$ & 0.056 \\
\hline \multicolumn{7}{|l|}{$\mathrm{N}$ staging } \\
\hline No & - & & & - & & \\
\hline NI & 2.391 & $0.67 \mid-8.514$ & 0.179 & 2.286 & $0.628-8.324$ & 0.210 \\
\hline N2 & 5.312 & $1.814-15.556$ & 0.002 & 4.629 & $1.576-13.596$ & 0.005 \\
\hline \multicolumn{7}{|l|}{ AJCC stage } \\
\hline 1 & - & & & - & & \\
\hline ॥ & 1.673 & $0.586-4.772$ & 0.336 & $1.85 \mid$ & $0.624-5.488$ & 0.267 \\
\hline III & 4.622 & $1.240-17.226$ & 0.023 & 6.857 & I.784-26.360 & 0.005 \\
\hline \multicolumn{7}{|l|}{ Differentiation } \\
\hline High & - & & & - & & \\
\hline Moderate & 2.255 & $0.799-6.362$ & 0.124 & 2.429 & $0.828-7.127$ & 0.106 \\
\hline Low & 5.000 & $1.354-18.469$ & 0.016 & 7.286 & $|.905-27.86|$ & 0.004 \\
\hline \multicolumn{7}{|l|}{ ZNRF3 index } \\
\hline Negative & - & & & _- & & \\
\hline Weak & 0.597 & $0.365-0.976$ & 0.040 & 0.642 & $0.369-1.115$ & 0.116 \\
\hline Moderate & 0.364 & $0.215-0.616$ & 0.001 & 0.452 & $0.256-0.798$ & 0.006 \\
\hline Strong & 0.246 & $0.121-0.499$ & 0.001 & 0.286 & $0.130-0.630$ & 0.002 \\
\hline
\end{tabular}

Abbreviations: DFS, disease-free survival; OS, overall survival; $\mathrm{Cl}$, confidence interval; HR, hazard ratio; T, depth of invasion; N, lymph node metastasis; AJCC, American Joint Committee on Cancer. 
Table 4 Multivariate Cox proportional hazards model for OS and DFS

\begin{tabular}{|c|c|c|c|c|c|c|}
\hline \multirow[t]{2}{*}{ Variable } & \multicolumn{3}{|l|}{ DFS } & \multicolumn{3}{|l|}{ OS } \\
\hline & HR & $95 \% \mathrm{Cl}$ & $P$-value & HR & $95 \% \mathrm{Cl}$ & $P$-value \\
\hline ZNRF3 & 0.574 & $0.416-0.874$ & 0.027 & $0.58 \mathrm{I}$ & $0.430-0.916$ & 0.032 \\
\hline $\mathrm{N}$ staging & $1.47 \mid$ & $0.95 \mathrm{I}-2.274$ & 0.083 & 1.344 & $0.849-2.128$ & 0.207 \\
\hline $\mathrm{T}$ staging & 1.717 & $1.021-2.886$ & $0.04 I$ & 1.608 & $0.937-2.762$ & 0.086 \\
\hline
\end{tabular}

Abbreviations: DFS, disease-free survival; OS, overall survival; $\mathrm{Cl}$, confidence interval; HR, hazard ratio; $\mathrm{T}$, depth of invasion; $\mathrm{N}$, lymph node metastasis.

studies have addressed that E3 ubiquitin ligases play an essential role in the regulation of many biological processes and as molecular targets for cancer therapy or biomarkers in carcinogenesis. ${ }^{14,15}$ Recently, it was reported that ZNRF3 is involved in human carcinoma and in a variety of cancerassociated pathways, and ZNRF3 has also been reported as a tumor suppressor in gastric and cystic pancreatic tumors. ${ }^{16}$ For the characteristics of ZNRF3 expression and function in colorectal carcinoma, some studies found that the stabilization of ZNRF3 in colorectal carcinoma could inhibit cell proliferation ${ }^{17}$ and ZNRF3 acts as a $\beta$-catenin target gene and functions in negative feedback loops via pathway ubiquitination-mediated degradation in cancer-related disease ${ }^{18}$ However, the ZNRF3 expression regulating proliferation and apoptosis in the context of colorectal carcinoma and its association with the prognosis survival of patients with colorectal carcinoma were unclear.

In this study, we investigated the ZNRF3 expression in colorectal carcinoma and revealed a different expression of ZNRF3 in colorectal carcinoma tissues and a significant correlation between IHC score of ZNRF3 negative, weak, moderate, and strong and the differentiation degree, $\mathrm{T}$ stage, and $\mathrm{N}$ stage of colorectal carcinoma. Generally results did not show a strong expression of ZNRF3 protein in colorectal carcinoma tissues compared with adjacent normal colorectal tissues. However, the strong expression of ZNRF3 in some colorectal carcinoma tissues showed a significant association with DFS and OS of colorectal carcinoma. Conclusively, analysis of univariate Cox regression showed that cases with strong or moderate expression of ZNRF3 showed an optimistic DFS and OS of colorectal carcinoma compared to negative expression of ZNRF3, and multivariate Cox model

A

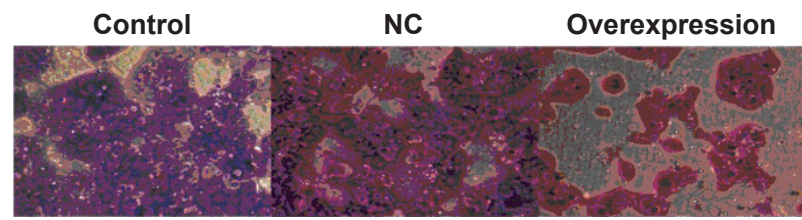

B

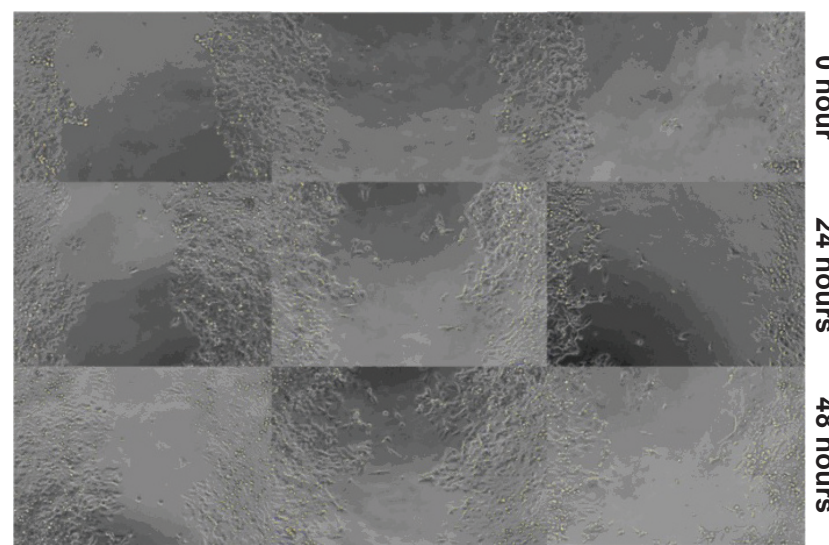

C
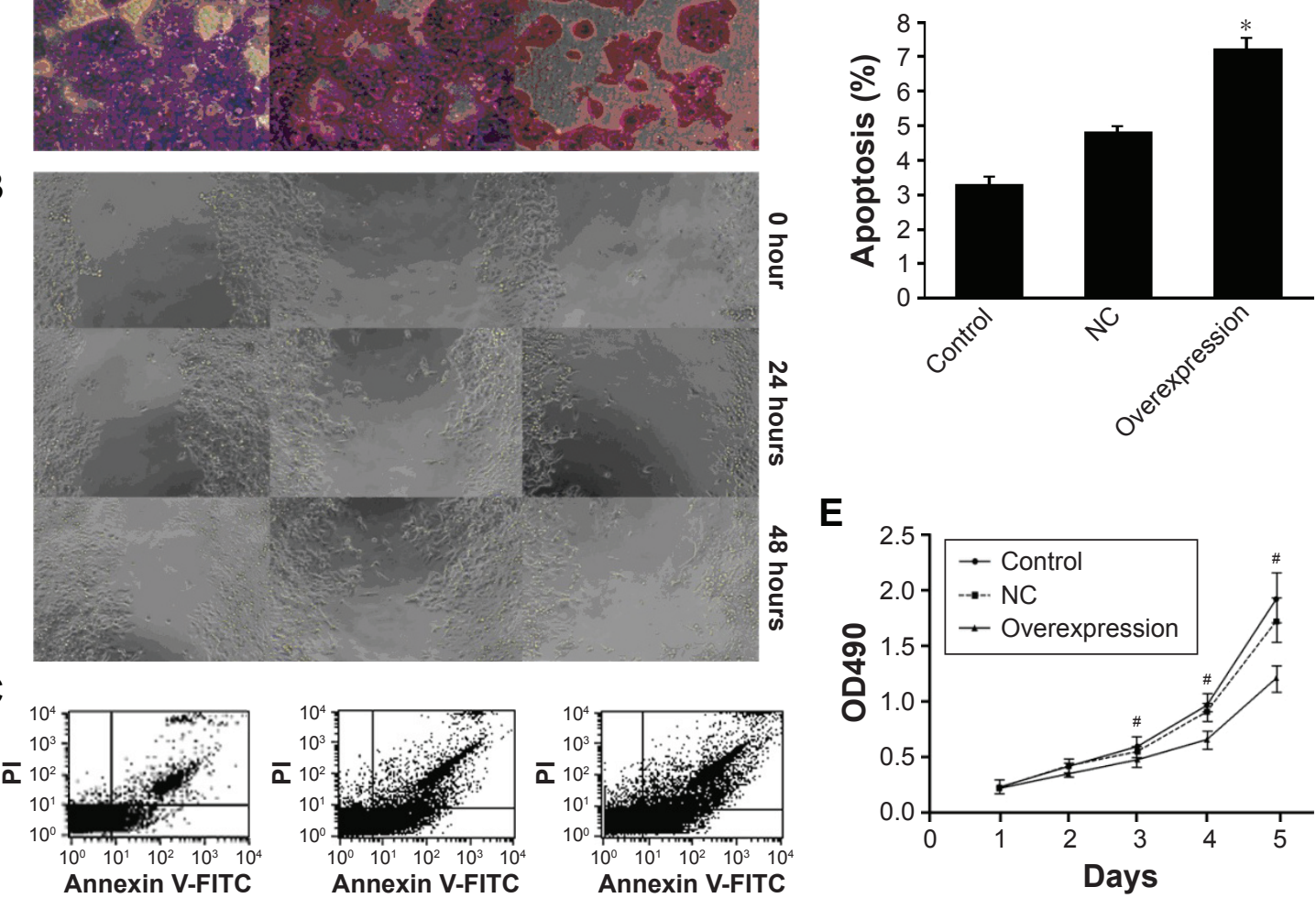

E

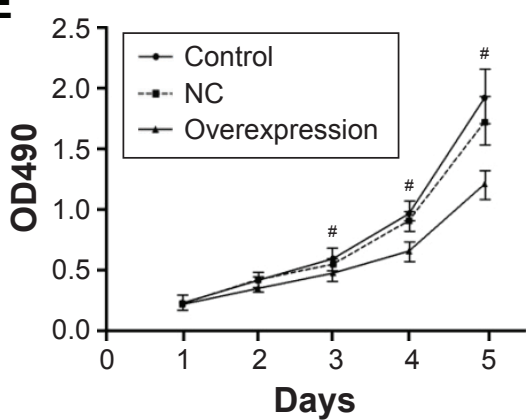

Figure 4 Effects of ZNRF3 on the proliferation and apoptosis of HCT-I I 6 cells.

Notes: Overexpression of ZNRF3 was achieved by transfecting with a plasmid containing ZNRF3. HCT-II6 cells transfected with a negative control plasmid and untreated cells (blank control) were used as controls. (A) Representative photomicrographs showing the migration of HCT-II6 cells in a transwell migration assay ( $\times 200$ ). (B) Representative photomicrographs showing migrating cells in a scratch wound assay (0 hour, 24 hours, and 48 hours) ( $\times 200)$. (C) Cell apoptosis was evaluated using Annexin V/PI double staining. (D) Early and late apoptotic cells were combined and are referred to as Annexin V-positive cells, which were used as the basis to calculate the percentage of cell apoptosis. (E) CCK-8 assays were performed to measure cell proliferation and survival at the indicated time points. All values are expressed as the mean \pm SD. $* P<0.05$, compared with the negative control; ${ }^{*} P<0.05$, compared with control.

Abbreviations: PI, propidium iodide; NC, negative control. 
Table 5 Analysis of apoptosis, proliferation, and survival in ZNRF3 transfection of HCT-II 6 cells

\begin{tabular}{|c|c|c|c|c|}
\hline $\begin{array}{l}\text { HCT-I I6 } \\
\text { cells assay }\end{array}$ & Times & CON & NC & OE \\
\hline $\begin{array}{l}\text { Annexin } \\
\text { V-FITC }\end{array}$ & & $3.310 \pm 0.210$ & $4.840 \pm 0.130$ & $7.260 \pm 0.260^{*}$ \\
\hline Survival assay & Days I-3 & $0.4|3 \pm 0.05|$ & $0.379 \pm 0.053$ & $0.347 \pm 0.027$ \\
\hline of CCK-8 & Day 4 & $0.966 \pm 0.042$ & $0.908 \pm 0.057$ & $0.658 \pm 0.047$ \\
\hline & Day 5 & $1.919 \pm 0.168$ & $1.719 \pm 0.201$ & $1.210 \pm 0.080 *$ \\
\hline
\end{tabular}

Notes: *Compared to NC, independent sample $t$-test $P<0.05$, data presented as mean \pm standard deviation.

Abbreviations: CON, control; NC, negative control; OE, overexpression.

also demonstrated ZNRF3 as an independent protection factor for OS and DFS $(P<0.05)$.

In vitro, following transfection with pEGFP-ZNRF3, a decrease in cell migration and proliferation and a significant increase in apoptosis were observed in ZNRF3-overexpressed HCT-116 cells. Furthermore, the decreased protein levels of $\beta$-catenin and TCF-4 were observed in ZNRF3-overexpressed HCT- 116 cells. $\beta$-Catenin/TCF is the main mediator of Wnt pathway, which is activated by binding of one of the 19 different Wnt ligands; following the activation of Wnt pathway, $\beta$-catenin phosphorylation and degradation are prevented, allowing it to accumulate in the cytoplasm and then translocate into the nucleus. The translocated $\beta$-catenin binds TCF/LEF as a coactivator, leading to transcriptional activation of the target gene, which is linked to the pathogenesis of diseases, such as colon carcinoma and leukemia. ${ }^{19-21}$ The present study suggested that ZNRF3 might function as a tumor suppressor via the suppression of Wnt $/ \beta$-catenin/TCF pathway in colorectal cancer.

\section{Conclusion}

Therefore, we conclude that downregulation of ZNRF3 in colorectal carcinoma tissue is closely correlated with human colorectal carcinoma, and individuals with higher expression of ZNRF3 have longer OS and DFS times, and the possible mechanism is related to a suppression of Wnt/ $\beta$-catenin/ TCF pathway, characteristic as active induction of apoptosis and a suppression of proliferation in colorectal carcinoma tissue. In summary, these results indicate that the higher ZNRF3 expression in colorectal carcinoma may be a novel biomarker of prognostic survival for colorectal carcinoma.
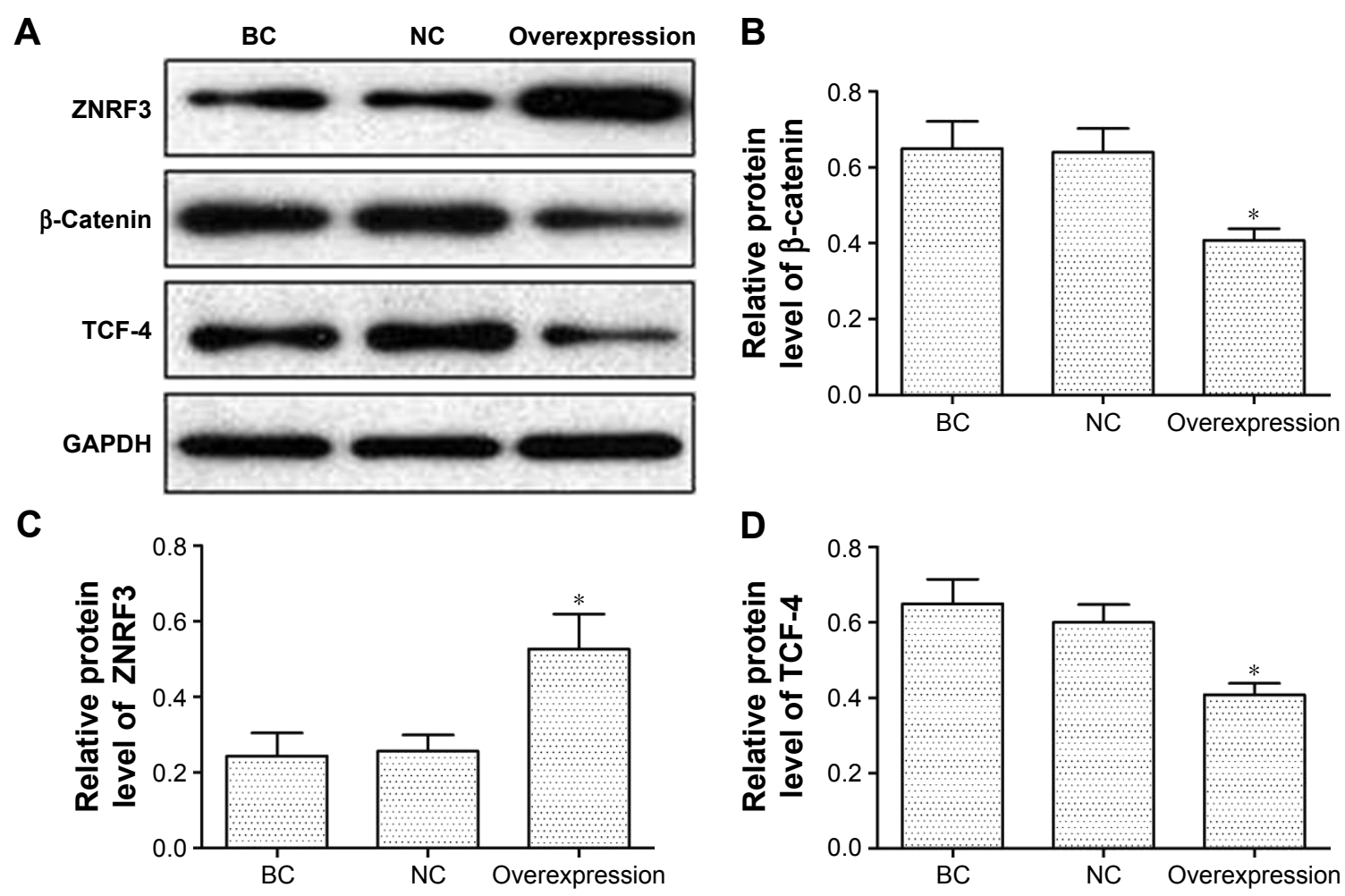

Figure 5 Effects of ZNRF3 on the expression of $\beta$-catenin and TCF-4 proteins in HCT-116 cells.

Notes: For the overexpression group, HCT-II 6 cells were transfected with PEGFP-ZNRF3, and for the NC, cells were transfected with an empty pEGFP plasmid. BC cells were not treated. (A) Western blotting analysis revealed a downregulation of $\beta$-catenin and TCF- 4 protein in HCT-II 6 cells. The membranes were blotted using $\beta$-catenin/ TCF-4 and GAPDH antibodies. (B-D) Results were normalized against the levels of GAPDH and are presented as the relative intensity. $* P<0.05$ compared with the $\mathrm{BC}$ or NC.

Abbreviations: BC, blank control; NC, negative control. 
Maybe, molecular therapeutic strategies based on ZNRF3 might be promising in the future for patients with colorectal carcinoma.

\section{Acknowledgment}

This study was supported by the Science and Technology Plan Fund in Hunan Province, People's Republic of China (2015SK2020 and 2015WK3011) and CSCO Clinic Tumor Research Foundation (Y-MX2014-002).

\section{Disclosure}

The authors report no conflicts of interest in this work.

\section{References}

1. Siegel R, Naishadham D, Jemal A. Cancer statistics, 2012. CA Cancer J Clin. 2012;62(1):10-29.

2. Ogino S, Lochhead P, Chan AT, et al. Molecular pathological epidemiology of epigenetics, emerging integrative science to analyze environment, host, and disease. Mod Pathol. 2013;26(4):465-484.

3. Ogino S, Stampfer M. Lifestyle factors and microsatellite instability in colorectal cancer, the evolving field of molecular pathological epidemiology. J Natl Cancer Inst. 2010;102(6):365-367.

4. Meyerhardt JA, Mayer RJ. Systemic therapy for colorectal cancer. NEngl J Med. 2005;352(5):476-487.

5. Meyerhardt JA, Giovannucci EL, Holmes MD, et al. Physical activity and survival after colorectal cancer diagnosis. J Clin Oncol. 2006;24(22): 3527-3534.

6. Lustig B, Jerchow B, Sachs M, et al. Negative feedback loop of Wnt signaling through upregulation of conductin/axin2 in colorectal and liver tumors. Mol Cell Biol. 2002;22(4):1184-1193.

7. Gupta A, Verma A, Mishra AK, et al. The Wnt pathway, emerging anticancer strategies. Recent Pat Endocr Metab Immune Drug Discov. 2013;7(2):138-147.

8. MacDonald BT, He X. A finger on the pulse of Wnt receptor signaling. Cell Res. 2012;22(10):1410-1412.
9. Koo BK, Spit M, Jordens I, et al. Tumour suppressor RNF43 is a stem-cell E3 ligase that induces endocytosis of Wnt receptors. Nature. 2012;488(7413):665-669.

10. Omran OM, Thabet M. Gelatinases A and B expression in human colorectal cancer in upper Egypt: a clinicopathological study. Ultrastruct Pathol. 2012;36(2):108-116.

11. Guo-Qing P, Yuan Y, Cai-Gao Z, Hongling Y, Gonghua H, Yan T. A study of association between expression of hOGG1, VDAC1, HK-2 and cervical carcinoma. J Exp Clin Cancer Res. 2010;29:129.

12. Youssef NS, Osman WM. Relationship between osteopontin and $\beta$-catenin immunohistochemical expression and prognostic parameters of colorectal carcinoma. Int J Clin Exp Pathol. 2015;8(2):1503-1514.

13. Wang K, Li N, Yeung CH, Li JY, Wang HY, Cooper TG. Oncogenic $\mathrm{Wnt} / \beta$-catenin signalling pathways in the cancer-resistant epididymis have implications for cancer research. Mol Hum Reprod. 2013;19(2): $57-71$.

14. Sun Y. Targeting E3 ubiquitin ligases for cancer therapy. Cancer Biol Ther. 2003;2(6):623-629.

15. Sun Y. E3 ubiquitin ligases as cancer targets and biomarkers. Neoplasia. 2006;8(8):645-654.

16. Wu J, Jiao Y, Dal Molin M, et al. Whole-exome sequencing of neoplastic cysts of the pancreas reveals recurrent mutations in components of ubiquitin dependent pathways. Proc Natl Acad Sci U SA. 2011;108(52): 21188-21193.

17. Wu C, Qiu S, Lu L, et al. RSPO2-LGR5 signaling has tumour-suppressive activity in colorectal cancer. Nat Commun. 2014;5:3149.

18. Hao HX, Xie Y, Zhang Y, et al. ZNRF3 promotes Wnt receptor turnover in an R-spondin-sensitive manner. Nature. 2012;485(7397):195-200.

19. Ma J, Wang R, Fang X, Sun Z. $\beta$-catenin/TCF-1 pathway in T cell development and differentiation. J Neuroimmune Pharmacol. 2012;7(4): $750-762$.

20. Barker N, Clevers H. Mining the Wnt pathway for cancer therapeutics. Nat Rev Drug Discov. 2006;5(12):997-1014.

21. Jamieson CH, Ailles LE, Dylla SJ, et al. Granulocyte-macrophage progenitors as candidate leukemic stem cells in blast-crisis CML. $N$ Engl J Med. 2004;351(7):657-667.
OncoTargets and Therapy

\section{Publish your work in this journal}

OncoTargets and Therapy is an international, peer-reviewed, open access journal focusing on the pathological basis of all cancers, potential targets for therapy and treatment protocols employed to improve the management of cancer patients. The journal also focuses on the impact of management programs and new therapeutic agents and protocols on

\section{Dovepress}

patient perspectives such as quality of life, adherence and satisfaction. The manuscript management system is completely online and includes a very quick and fair peer-review system, which is all easy to use. Visit http://www.dovepress.com/testimonials.php to read real quotes from published authors. 